\title{
Learning in executive management education
}

\section{Aprendizagem na educação gerencial de executivos}

\author{
Daniel Jardim Pardini ${ }^{1}$ \\ Carlos Alberto Gonçalves ${ }^{2}$ \\ Ana Cláudia Azevedo 3
}

\begin{abstract}
A new challenge in executive education is to develop distinct learning models from the traditional MBAs and other management courses. Revisiting the literature in management education we adopt the social constructivist epistemological approach to discuss and propose a network learning model in the acquisition of knowledge by executives. The results of the research suggest that the network learning method improves the relationship between executives to change and acquire knowledge and, more than other specific management models, the role of the teacher is facilitate the interrelationship between the participants to discuss their experiences and decisions concerning high complex managerial situations.
\end{abstract}

Keywords: Management Education. Executives. Learning Network Model. Knowledge Network.

\section{Resumo}

Os novos desafios na educação gerencial perpassam o desenvolvimento de modelos de aprendizagem diferentes dos oferecidos por programas de MBA e outros cursos destinados à gestão. Ao revisitar a literatura de educação gerencial, adotamos uma abordagem epistemológica construtivista para discutir e propor um modelo de aprendizagem de rede destinado a executivos. Os resultados da pesquisa sugerem que o método de aprendizagem em rede aumenta a interação entre executivos na aquisição e troca de conhecimento. E, mais do que propagado em outros cursos

1 Doutor em Administração pela Universidade Federal de Minas Gerais. Professor do programa de Doutorado e Mestrado em Administração da Universidade FUMEC. E-mail: pardini@fumec. br - (31) 3269-5230.

2 Doutor em Administração pela Universidade de São Paulo. Professor associado na Universidade Federal de Minas Gerais e na Universidade FUMEC, nas Faculdades de Ciências Econômicas e Ciências Empresariais. E-mail: carlos@face.ufmg.br - (31) 3269-5230.

3 Mestre em Administração pela Universidade FUMEC. Professora do curso de Administração da Faculdade de Nova Serrana. E-mail: prof.ana@fanserrana.com.br - (37) 3226-2610. 
específicos de gerenciamento, o papel do professor é facilitar o inter-relacionamento, a troca de experiências entre os participantes na discussão de experiências as decisões em situações de alta complexidade gerencial.

Palavras-chave: Educação Gerencial. Executivos. Aprendizado em Rede. Rede de Conhecimento.

\section{Introduction}

Education of executives is one of the biggest challenges for business schools that propose to coordinate a learning process concerning managerial class. Different from what is taught at the university management courses, the knowledge diffusion for executives learning follows an own logic method that is far from the conventional pedagogical teaching of student-professor process. What differentiates the networks learning programs directed to executives from other conventional programs of management and which is the appropriated configuration for the consolidation of this educational arrangement consist the research questions that this study intends to investigate.

While much has been published on the dissemination of management knowledge (Anderson \& Engwall, 2003; Armstrong \& Mahmud, 2008; Waller et. al., 2014) and about specific aspects of international universities activities (Mclntyre \& Aloan, 2005; Pless et. al., 2011), researches done with the intention to understand the dynamic learning oriented to executives are rare. One of the reasons that justify the search for a specific learning program for executives is the need to avoid the so called "loneliness power" syndrome. The executive feels the necessity to open himself with his pairs to share know-how and to exchange experiences about high complexity situations of management that the graduation, post-graduation and traditional executive programs are not able to offer.

The study of executive learning process provides an opportunity to make important contributions to literature. Although some authors (Andrade \& Nakata, 2013; Rousseau \& Mccarthy, 2007; Kaiser \& Kaplan, 2006) have developed conceptual frameworks of learning theories, the 
amount of empirical researches in non-traditional education approaches is rather limited. A major thrust of executive education concerns in disseminating self-views of one's competence as commander into alignment with other's leader views (Hogan \& Warrenfeltz, 2003). From this point, the challenge of business schools specialized in executive programs is to adopt pedagogical methods that cross over the traditional interventions used to train corporate groups.

In opposite to the traditional learning process, the network method proposed in this study constitutes a cooperative arrangement, where the actors, simultaneously, seek to supply the organizational demands and offer some know-how to the other partners. The relationship between the participants should attend the principle for a complementary and balanced contribution from the partner in the acquisition and exchange of knowledge. This intensive interaction between the partners to supply and provide demanded resources, differ the network learning from other executive education programs.

Given the intensive growth in executive education and the unheard of a similar learning approach, we purpose to investigate a network learning process implemented by a Brazilian Business School- Fundação Dom Cabral Foundation - FDC. In the course of its history, FDC has developed a number of partnerships with groups of companies. The main differential of the program is the qualification of the executives using the network learning format. The institution offer three partnership programs to CEO's, directors and executives that we will discuss in this paper to attend groups of: a) large national and multinational companies, b) top management of medium companies and c) shareholders of family companies.

\section{Learning in management education: concepts and epistemological dimensions}

In the literature we identify three orientations that could be important in the management education discussion: the gestalt theory, the behaviourism and the social and situational view. According to the gestalt 
theory, originated in Austria and Germany, learning is the result of mental models of the world used by people to interpret reality and guide their behaviour. The gestaltists hypothesize that an individual's perception of stimuli has an affect on their response (Rock \& Palmer, 1990). So, if two individuals are exposed to identical stimuli, their reactions to it would be different, depending on their past experiences. From this view, learning is defined as "consisting of the creation of trace systems of a particular kind, the consolidation of these aggregates, and the increased availability of these trace systems in repeated and in new situations" (Blosser 1973 p.45).

Another concept of learning can be found in the behaviourism tradition, which still dominates the literature of American psychology. In this view learning is a change occurred in behaviour after a personal experience. The purpose in education is produce behavioural change in desired direction (Merriam \& Caffarella, 1991). This involves acquiring or changing behaviours. Here is important to introduce the concept of skill, a particular kind of behavioural capacity, a special ability to do something. Conversely the gestalt model of learning, which see management education as a process of constructing models to interpret organizational phenomena, proponents of the behaviourist model assume it as a process of acquiring skills (Hogan \& Warrenfeltz, 2003).

The third orientation of learning involves the social and situational views. Learning is conceived by the interaction and observation of the social context (Merriam \& Caffarella, 1991). The locus of learning is in the relationship between people and environment and the education purpose bring close to the concept of communities of practice, in which conversation and participation are stimulated to occur. This idea that learning involves a deepening process of participation in a community of practice has gained significant ground in recent years and become an important focus to the development of organizational groups, basic fundament in networking education.

Epistemological dimensions of instruction from the general literature in education also could be useful to understand executive 
learning approaches. Objectivism, derived from the stimulus-response theory (Skinner, 1935) and constructivism based on the assumption that knowledge is created or constructed by every learner (Larochelle, et. al., 1998) are two important issues in the discussion of learning procedures. The objectivist perspective consists of transmitting knowledge from the professor to the students and allowing each student to dominate this learning. This approach is based on the traditional methods of learning focus in a unidirectional construction of knowledge. Some critics of objectivism argue that learning is impoverished when individuals are passive recipients of content that is delivered to them (Arbaugh \& Benbunam-Fish, 2006).

In contrast, the premise of the constructivist perspective is that knowledge is created or constructed by every learner. Using the constructivism approach, concepts are better discovered and operable than when they are instructed. In social constructivism teaching is a sharing experience where knowledge is created trough constructive dialogue and group discussion. Consequently, the role of the instructor may be restricted to select groups based on common interests, to intermediate the construct of knowledge and to synthesize key ideas from group discussions (Hung \& Nichani, 2001). Within constructivism we can find two distinct schools of thought: individual, which assumes that knowledge construction occurs in the student's head, and social which assumes that knowledge is socially constructed in the world. Our approach in this study concentrates in the second one.

The group learning perspective is based on the notion that individuals learn more when they construct, discuss and change knowledge in group. This methodology includes the opportunities to share different types of skills to discuss resolution of disagreements and to provide explanations for the partner's doubts. As observed by Arbaugh and Benbunam-Fish (2006), the group-learning approach is fully developed in constructivism. The role of the instructor in this environment may be restricted to facilitate the constructive dialogue and group discussion. 
In social constructivism learning occurs most effectively when individuals interact with other to develop a new knowledge. The partners contribute with this construction bringing their experience to the group. Cooperative arrangements could reduce uncertainty, give flexibility to the decisions to deal with the market, assure speed to give answers to the environment and obtain up-to-date information about the business world (Child et. al., 2005). The same motivation seems to occur when top management decides to acquire new knowledge and competences in learning networks. In general, the manager is interested in reduce the apprehensions in relation to the market threats, to know the emerging innovations and to search for new management models as a way to improve the organizational results.

\section{Method}

To investigate what distinguish the executive network learning methodology from other traditional management programs we study the Dom Cabral Foundation case, according to the Financial Times ranking, one of the 20 best business school in executive education in the world. The interviews of this research were made with 32 staff members and professors of Dom Cabral Foundation which were directly involved in the partnership programs. We also interview four executives that integrate the partnerships groups. To identify the differentiations of the executive's network learning and understand how it worked, semi structured interviews were conducted with the dean, directors, managers, professors and administrative staffs of FDC.

Our research has applied the thematic content analyses to investigate the network learning process adopted by FDC. Thematic analysis is a search for themes that emerge as being important to the description of the event. It is a form of pattern recognition within the data, where emerging themes become the categories for analysis (Fereday \& Muir-Cochrane, 2006). The method involves the identification of themes through careful reading and re-reading of the data. In this task, qualitative software could be helpful. The coding process involved recognizes an 
important moment and encodes it to a process of interpretation. A "good code" is one that captures the qualitative richness of the phenomenon (Boyatzis, 1998, p. 1). To classify the codes we used the ATLAS-TI software. After that, ten themes associated with the network learning process were identified.

\subsection{The partnership programs}

The partnership programs implemented by FDC are corporate arrangements where organizations participate to simultaneously fulfill their demands for specific resources while offering know-how to the other partners. Relations among participants must be complementary and balanced during the exchange and acquisition of knowledge. Within the educational context of the business partnerships, FDC plays the role of facilitating the dialogue and coordination that stems from the exchange of generated knowledge rather than that of an intervening party or consultancy in organizational management.

These Programs are not limited only to courses and seminars offering management programs to shareholders/owners or executives. They also include developing management methodologies, techniques and tools as well as incentives for the exchange of experiences among partners. This occurs within an environment of ongoing group learning backed by cooperative actions. The participants share financial, human and technological resources in order to ensure the feasibility of specific projects.

Executive education is one of the greatest challenges for institutions that propose to coordinate a learning process aimed at companies. Unlike teaching in traditional business management programs, disseminating knowledge through partnerships is a two-way street. On the one hand, knowledge manifested of the situation of the organizational environment is pictured by executives. On the other, the theoretical bases that are the foundation of organizational concepts and practices are revealed and expounded upon by the faculty. 


\subsection{Centre for Business Technology (CTE)}

CTE is a partnership launched by FDC in 1989. It is aimed at large local and multinational companies that gather within a network to generate and disseminate knowledge. The intra-business contact afforded by the network is intended to increase the companies' perception of the business environment and support analyses, studies and discussions that produce replies from the strategic movement of the partner companies while always striving for increased competitiveness.

Consequently, the development model of the partnership is intended to affect three sectors of results: knowledge sharing, research and knowledge generation and executive training and development. Twenty-three large companies comprise the Partnership and members contribute annual dues that go into a fund that provides for the group's activities.

Each partnership appoints a representative that has an active voice in the Development Committee, besides being the principal contact of his company with CTE. This committee is coordinated by a representative elected by the companies and by the CTE manager. It has the task of running the partnership through the conjoint preparation of an Annual Directing Plan, whose make up encompasses all the activities to be undertaken over the following 12 months.

\subsection{Partners for Excellence (PAEX)}

PAEX was created in 1992 and it is a partnership between FDC and groups of medium size companies with the same degree of complexity of management that seek to develop themselves based on the construction and application of knowledge in management. It is intended to encourage companies in their search for excellence in management through a process of exchange and learning by improving results, increasing competitiveness and creating the bases for the permanent establishment of these partners' organizations. The executives and the companies seek this excellence based not merely on what is provided by FDC's 
professors but also by the executives of other companies at a similar stage of evolution and needs. It is an opportunity to take advantage of learning that derives as much from the successes as from the failures of medium-sized growing companies.

In 2008 PAEX encompasses 270 companies organized into 35 regional groups in Brazil, Paraguay, Chile, Argentina, Ecuador and Colombia. Each group is made up of up to ten companies from the same region. This facilitates exchange and access to the activities, and keeps directors from having to move from their territorial base.

Activities within PAEX allow the participation of a large number of executives from each company, which favors the formation of a critical internal mass, the groups evolving in cycles, with deepening content following the rhythm of the companies' evolution and growth. PAEX seeks quantitative and qualitative results with improvement in: a) economic-financial results; $b$ ) the redefinition of the company's strategy based on an integrated model; $c$ ) the definition of performance indicators for the organization; $d$ ) a periodic follow-up of goals; e) the redesign of typical processes with greater impact on results; $f$ ) the realignment of the company's commercial strategy and the rethinking of its own business.

PAEX management methodologies are developed to be applied in the companies in order to improve their competitiveness and optimize their global results. From the business project, auxiliary methodologies in the fields of finance, marketing, processes, people, logistics and operations are implemented in each one of the partner companies of each group to guarantee the range of results desired by the companies.

\subsection{Partnership for Shareholder Development (PDA)}

PDA is a partnership that has been developed and run by FDC since 1999. In this program the partners are part of a group of family businesses. This Program is for members of shareholding families willing to ensure continuity for their companies. The mission of the PDA program is to develop current and future shareholders in families that own and 
control their companies so that they can more effectively carry out their responsibilities, exercise their prerogatives and rights, preserve and expand family equity and help achieve long-lasting life for their company while, at the same time, providing support to reflections on familycompany leader succession.

The partnership's main objective is to create a common language and prepare future shareholders to act as capital managers, seeking ways to ensure long-term maximization of the invested capital while developing competencies, taking on basic responsibilities, such as company management and business equity, understanding the roles of shareholders and managers in terms of rights and obligations - and the interaction between both - and also integrating themselves into the companies' organizational complex, each one playing his/her ideal role.

Companies vary in size and in level of revenues, as many are at the development stage. Most participants are basically current and future shareholders who are committed to the program's aims. They invest their time in this partnership program trusting in the exchanges and fine synergy among other family companies as a way to advance their organization's development process. More than 90 family companies have joined the PDA activities since it was created. At the moment of this study, the PDA program comprised 6 working groups in different regions in Brazil.

The topics broached during the program involve the dynamics of the family/business system that deal with the work relationships between family relatives and non-family professionals, leadership roles in family companies, family business conflicts, the mechanism for family participation in their property, and ensuring professionalism in equity and company management. When dealing with the issue of transition management the program includes preparing successors for equity and business management, developing planning for the coming generations as shareholders and members of the company-owning families, and conflict and tension management. 


\section{Results}

Ten thematic categories were identified and divided according to the moment - before and after - the decision of being part of an executive partners group (FIG.1). At the stage that precedes the beginning of the partnership program we discuss the principles of network learning, the motivation of executives for seeking new sources of management knowledge, as well as the importance of trust to start and develop program activities. At this preliminary stage we also refer to the attributes 'negotiation process' and 'selection criteria' that are needed to become part of the groups. The two subsequent stages refer to the themes related to program management and tools used to reinforce cooperation within the groups.

Figure 1 - The stages of the network learning process

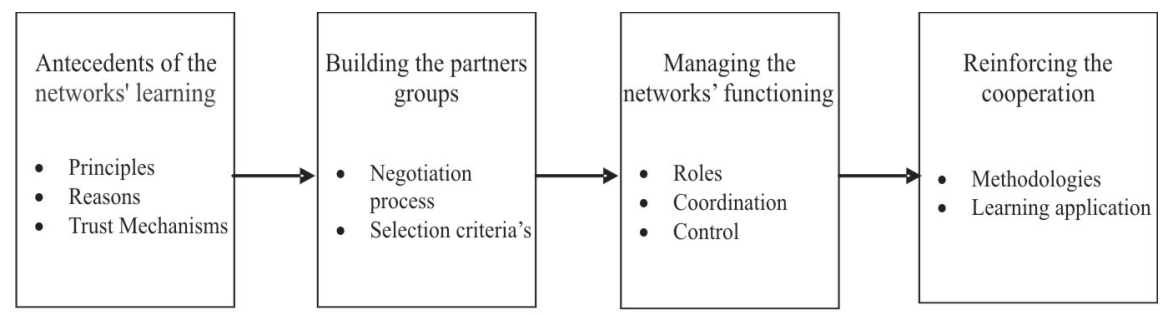

Fonte: Developed by the authors.

\subsection{Antecedents of network learning}

The themes selected that are related to the antecedents of the learning process deal with the principles that guide network learning, the justifications in belonging to a group of partners and the trust that must be built in relations among executives.

\subsubsection{Principles that guide business learning networks}

This thematic category broaches the pillars on which partnership projects are built. We present the principles drawn from the current 
research that will not only serve as the basis for partnership development but also guide it.

- "Work with companies, not for companies"

One of the main pillars of learning networks that was highlighted by interviewees refers to "working with companies ". This connotation refers to the intention to approach organizations and their main leaders in a way that is more cooperative than interventionist. It can be perceived from the words of network users that, in a cooperation environment, the aggregating influence of the institution in charge of coordinating the learning process facilitates the exchange of knowledge among partners and leads to greater trust in the work developed.

- Open climate for exchanges among partners

The groups must be inclined towards exchanges and, therefore, companies must be ready to behave transparently, since an open exchange of information and experiences is fundamental in setting up a group. It is vital that the main leader of a company be present at meetings, not only for his/her company to be accepted into the group but also to become a reference of commitment and openness for the other members of his/her organization.

- Equal treatment for all participants

Equality is another relevant principle that was highlighted by interviewees. It means that the benefits of the collective would overcome any individual interest. Thus, specific needs that do not fit into the nature of the partnership must be dealt with in particular, which makes it important to balance the complementarities and specific interests that organizations bring to discussion groups. An excess of demands, when compared to the contributions that a company makes to the partner network, can lead to disproportional treatment in relation to the other companies in the network.

- Understanding the working dynamics of a partnership

Among the issues needed to coordinate the activities of partnerships we will find the understanding of the dynamics of learning networks. It 
means mastering their workings, being aware of what a partnership really involves and being available to the organizations that make up the groups of partners, all the while being committed to the goals of the parties involved.

\section{- Knowledge organization}

One of the principles of FDC partnerships is that organizations themselves have much knowledge to be explored. Due to time constraints, it oftentimes happens that organizations do not notice the potential of the information underlying their management areas. The proposal put forth by the work groups in the partnerships is that of following-up the success and failures of the companies, appropriating, organizing, systematizing and continuously improving on this knowledge.

\subsubsection{Reasons for being part of a group of partners}

One of the factors listed in the interviews that will justify the quest for a business learning network is related to avoiding the so-called "loneliness of power" syndrome. Executives decide to become part of a group of managers as a way to be able to talk to their peers from other organizations and thus share and exchange experiences and suggestions for situations of high managerial complexity. Through contact with other managers it is possible to observe a broader picture of business reality from different visions.

Furthermore, it is a chance to seek answers for emerging issues in one's own company, and as these are debated they reduce the anxiety that stems from dealing with the fear of the unknown. The network learning process itself leverages the improvement needed for the alternatives that will lead to the decisions that can decrease the uncertainties one has to face within an organization's environment.

The justifications to be found in the search for partnerships will vary according to the nature of the programs. The organizations that look to the Entrepreneurial Technology Center - CTE intend to speed up organizational learning so as to obtain new competitiveness and 
performance channels. Generally speaking, these are the leaders of large corporations who wish to exchange knowledge with other companies to gain access to new management models, validate organizational practices and learn best practices by basing themselves on other managers' perspectives (Fundação Dom Cabral, 2005b). As the program is broadened to reach other hierarchical levels, it not only increases its competitive variable but also enhances and updates people, which become a further source of attractiveness.

At PAEX, the need to enhance management and the financial limitations of small and midsize companies to pay for specific management support services lead to some factors that will make the owners of these companies to seek partnerships. The chance to take part in continuous learning activities attracts small and midsize businesses, and this kind of demand for constant updating is one of the motivations to remain in a program even after the end of group activities.

The reasons that make leaders join PDA are related to their concern in educating heirs who may or may not take an active part in the family business, and preparing them to act as shareholders and counselors to the company. Most of the time, the motivation to join a PDA group stems from recommendations from other businesspeople who belong to the network or from invitations made by FDC to companies who are known for their family tradition. These are managers who are interested in gaining a better understanding of family-company relations.

\subsubsection{Trust mechanisms}

When an association of businesspeople proposes to go through an experience of knowledge exchange while being coordinated by a mediator, it is essential that strong personal trust relationships be established to make sure the group will last. The need for an intense exchange of information about products, services, production means, and management, considerably increase the relevance of trust in interpersonal and inter-organizational contacts. Besides its being an 
important mechanism in coordinating business groups, trust must be dealt with as a precondition for the development of learning activities.

The people we interviewed stressed that trust can only be gained by degrees. Progressive talks about the internal affairs of member organizations contribute to bring about an environment of loyalty within the group as to the discretion, wisdom and confidentiality that must drive relations among partners. At such a moment, the role of the facilitator who will promote good will among the partners is of fundamental importance for the survival and development of the group of managers. The level of trust among the executives in the groups will naturally increase as the meetings go on happening. The barriers put up by initial apprehension are torn down, and the growing awareness that it is possible to learn from each other leads to their setting up a network of "informal counselors".

Furthermore, some of the procedures are formalized by contract to strengthen group commitment to rules of conduct. FDC acts as a mediator in building up the bases of trust of partnership programs. The use of group integration dynamics can smooth over possible behavioral impediments while carrying out knowledge exchange sessions. Competitors will never take part in the same group and the confidentiality of the information is dealt with at the first meeting.

\subsection{Building groups of partners}

\subsubsection{Negotiation processes}

In the formatting or designing phase, undertaken conjointly between FDC and the company, the idea or vision is defined, partners are identified, objectives are defined, rules and functioning criteria are established and roles and responsibilities are defined.

The idea of setting up a partnership can stem from one company only or from several simultaneously, through the school that will manage it. It can arise also from a future challenge, from a current market imposition, from dissatisfaction with traditional methods of development or even from the search for differentiated and integrated forms of exchange and 
development. The idea is made explicit and detailed by an FDC team and it will represent the vision or strategic objective that will permeate the Partnership during the whole period of its execution, besides serving as a basis for the search and selection of companies that may be interested in participating and that have a common and shared objective. One should not lose sight of the fact that, in addition to everything else, the companies will be developing a culture of collective learning.

At the moment of negotiation, the scope and objectives of the partnership are established, durations, necessary investments and resources to be invested by the partners, criteria for the assessment of actions, rules for entering and withdrawing from the partnership, property of the knowledge generated, definition of the roles and responsibilities of the parties involved, management mechanisms and the overseeing of the actions are defined.

\subsubsection{Criteria to select a partner}

The selection of partners should be dealt with very carefully to ensure every prospect of future success for the partnership from its early stages. Potential partners can emerge from personal contacts and friendships, through conferences, recommendations, associations of companies or publications.

Normally, a tabulated profile is drawn up to evaluate potential partner companies. The criteria for this take into account not only the results that are expected from the program, but also the contribution that each company can bring to the partnership.

In selecting a partner that will take part in a cooperative learning process, it is necessary to previously analyze the compatibility of goals. As we have previously mentioned, one of the principles of cooperative arrangements involves the balancing of the contributions made available throughout the network. It is understood that an organization whose goal it is to achieve a new strategic position with the knowledge it will acquire from other partners will have some kind of know-how to offer and share 
with the other participants. It is the complementarity of knowledge made feasible by the exchange of experiences among organizations that will energize network performance.

Based on the manifestations of those who were interviewed, it was possible to identify the criteria that must be followed in setting up a group. The preconditions to set up a business learning network will vary from program to program according to the nature and goal of each one those programs. For example, being a competitor of one of the organizations that already belongs to one of the groups will be an impediment to PAEX participation. Such a condition could inhibit the exchange of experiences among members of the group and compromise the open environment that is conducive to new knowledge within the network.

The non-competition criterion is justified by the need for a spontaneous and open relationship environment to permeate the group of partner companies. Thus, a company in the same industry as that of an organization that seeks to become a member of the network can veto its competitor's bid to become a member of its group.

As for PDA, the competition factor is made irrelevant due to the program's own goals, namely that of training and developing shareholders and, therefore, an exchange of experiences among possible competitors that belong to the same group is still feasible. As a matter of fact, such similarities can bring about good opportunities to discuss and exchange knowledge on common experiences.

Another issue that must be taken into account in setting up a partnership network is that of the size of organizations. Network compatibility depends on the similarity in size of the companies chosen to make up a group. It does not mean that differences in size would be an excluding factor (revenues and profit margins, for example, can vary from company to company), but the organizations at hand must have the same level of complexity and people available to absorb the learning involved.

The ethics issue is also taken into account in selecting the company that will be part of a group. The strong interaction among 
partners, which result from a long-lasting relationship among executives in learning networks, will inevitably lead to a great degree of closeness among participants within the groups. It is obvious that deviations in organizational management behavior will compromise a company's participation in a group; the same is valid for negative impacts on its reputation and image.

The number of participating companies within a group varies from program to program. In PAEX, this number can vary from 6 to 12 companies per group. PDA works with an average of eight organizations in each group. Guidelines dictate that all companies within a group should begin and end the program established for the partnership together. As for CTE, it is only one group of organizations that will share the activities of the partnerships.

After partners have been identified and selected, the necessary time is invested in efforts to negotiate the goals of the partnership and to establish the rules and criteria of its functioning.

\subsection{Managing the functioning of the network}

\subsubsection{Roles}

FDC is responsible for the coordination and control roles, which is runned by a manager appointed to each partnership, who coordinates the tasks involved. The group manager is responsible for all contact with the companies and for following up the partnership's activities.

One condition that was highlighted in the interviews and that is needed to perform the role of manager in partnerships is linked to the "seniority" needed to discharge this function. It is assumed that an individual who is ready to bring FDC and clients together will have good business experience, the skills to move within the executive environment and a good academic education. These are characteristics that can only be acquired with the passing of time and with long experience in the business environment. 


\subsubsection{Coordination and control}

The relationship between the companies in the implementation phase of the partnership requires coordination, long term common perspective, acceptance of mutual adaptation and incremental innovation. Thus, FDC prepares a work plan detailing the specific objectives of the partnership, the companies agree to it and it guides the implementation process. It is evaluated at the end of this stage.

The existence of a focused coordination and steering committee is indispensable. It is made up by representatives from each of the companies and carries out the tasks of following-up, coordinating and assessing the activities performed.

Funds, technological resources and personnel are made available for the activities of the partnership.

The permanent involvement of the strategic leaders is a way to achieve commitment to the partnership and an example that motivates other members of the company.

Follow-up is carried out in loco, that is, the coordination should be physically present in the companies, talking to the directors, to middle management and even to the other collaborators. Their presence allows them to assess not only the "climate" of the partnership but also the effective and applicable results for the companies. They can also check if the needs indicated remain the same and identify new needs.

These evaluations take into account measurable and nonmeasurable aspects that can impact the company in the short, medium and long terms. In special, they deal with the learning absorbed, the cultural exchanges and opportunities generated and aspects related to content (results planned and carried out), to process (quality of interaction, decision-making process, involvement and participation of the parties, speed and rhythm of the activities, management of the interfaces), in addition to the byproducts generated. The frequency of following-up and of evaluations depends on the schedule established for the Partnership. 


\subsection{Reinforcing the cooperation}

As a mechanism to reinforce cooperation, partnership groups use cooperation strategies that make easier to learn and apply the concepts. Socialization strategies are processes to generate and transmit learning to the people who will take over some kind of role within a social environment (Van Maanen, 1978). They can be used for novices those who are newly-arrived and who need to learn more about the goals and the other people who make up the social group. Within partnership programs, these are translated into integration techniques that work as synergetic impulses for members to get to know each other and format some social commitments. On the first contact with the managers of the partnering companies, an agreement is established for the functioning of the partnership. Expectations about programmed content, rules of conduct, the goals and priorities of each company; all these issues are dealt with. This first contact makes it possible to get to know the profile of the participating leaders and their demands as to relevant content that will be discussed within the network. Thus, each partnership carries out socialization strategies among its participants according to the goals to be reached during the development of the program.

Following up on the socialization stage for partnership members leads to a full program directed at exchanging information among leaders. Generating knowledge in learning networks entails several meetings which are included in the agenda of the networks. These are discussions centers that are structured to make it possible to exchange experiences among the representatives of the partnering companies and they work as debate forums that define the themes that interest the group and that will be explored during the program. The dynamics and the structure of these meetings will vary from one partnership to another.

\subsubsection{Methodologies and the application of learning}

The learning carried out in the networks that were studied is related to the process of acquiring new management knowledge. Its result is related to incorporating a new competence that will later be applied in 
organizations. As to learning generated within the network, its aim is to improve available knowledge and the skills of the participant not only through the exchange of experiences with other leaders but also by applying specific methodologies.

The assumption for the methodologies is that change in organizations cannot operate only through exchanges. Companies need a platform of common concepts that can work as a language to facilitate exchanges. Therefore, applying concepts to practice will reinforce cooperation among the partners (Waller et. al., 2014).

Through its professors, FDC transmits the concepts and methodologies, coordinates their implementation, follows-up and monitors the different stages of content application directly at the company site. The noncompetitive environment among partners is also conducive to a company executive's counseling or even teaching another network member. Learning dynamics are always directed towards an intense participation of the organizations in a quest for solutions to the themes presented.

As to CTE, its methodology is based on enabling both the main leaders and also the other executives of participating organizations. The content that is dealt with involve meetings to discuss innovative management models, research on organizational management issues that deal with business globalization and with the building of organizations that act in a sustainable way within the business environment.

Meeting content makes it feasible to structure cases and publish research and books on subjects of interest to the companies by broaching subjects related to success strategies, organizational structure and culture, logistics, productive chain, corporate governance, e-business and other studies on management and competitiveness.

In PAEX, companies seek to develop a business project by establishing long-term vision, competitive strategies, and the balanced scorecard that will lead to actions in the areas of marketing, humanresources, finance, logistics, processes and cost. 
PDA analyzes and discusses tools that can help family businesses to define their strategic focus, aligning the interests of partners, the structure of corporate governance and succession planning.

\section{Conclusions}

The objective of this study was to find the differentials of executive networks learning programs and which is the pertinent configuration for the consolidation of this educational arrangement. It discusses a network learning format as an alternative way to improve the competences and knowledge of executives.

The study shows some aspects that differentiate the company's networks from other management learning methodologies.

The learning core is dislocated to the environments group. The professors share with the company the responsibility to teach and learn. Thus, the knowledge is produced within the enterprise groups and after applied by the organizations.

Additionally, the permanent contact of the business school with the organizations occurs in a much more effective way than other type of programs. This could be justified by the need of a frequent observation of the company's evolution at the period of duration program.

The learning process must be planned and customized considering the characteristics of the participant companies. The same flexibility doesn't occur in other programs. Different from other courses, the partners' programs maintain intense interorganizational relations.

It was observed that in certain occasions the managers of the organization keep a relationship of experiences' exchange independent of the planned activities. And, in contrast to the degree programs and traditional executive education, conducted by professionals with academic formation, the profile of the people in charge to the activities of learning at partners' networks must, preferentially, hold management and academic experiences. 
In final conclusions, this paper intends to uncover some of the hidden dimensions in executive education. We suggest that understanding hidden ways in which this arrangement works could be the beginning to the debate concerning best methodological practices in management learning.

\section{References}

Anderson K. S., \& Engwall L.(Eds.) (2003) The expansion of management knowledge: carriers, flows and sources. Pale Alto, CA: Stanford University Press.

Andrade S. M., \& Nakata L. E. (2013) Aprendizagem sob o olhar dos executivos: um estudo sobre organizações que pretendem se destacar pela qualidade do ambiente de trabalho. Revista Capital Científico. Vol. 11 n. 1 - Janeiro/Junho 2013.

Arbaugh, J. B., \& Benbunan-Fich; R. (2006) An investigation of epistemological and social dimensions of teaching in online learning environments. Academy of Management Learning \& Education. Vol. 5, No. 4, 435-447.

Armstrong, S. J., \& Mahmud A. (2008) Experiential learning and the acquisition of managerial tacit knowledge. Academy of Management Learning \& Education. Vol. 7, No. 2, 189-208.

Blosser, P. (1973). Principles of Gestalt psychology and their application to teaching junior high school science. Science Education, 57, 43-53.

Boyatzis, R. (1998). Transforming qualitative information: Thematic analysis and code development. Thousand Oaks, CA: Sage.

Child, J., Faulkner, D., \& Tallman, S. (2005) Cooperative Strategy Managing alliances, networks and joint ventures. Oxford University Press, $2^{\text {nd }}$ ed.

Fereday, J., \& Muir-Cochrane, E. (2006) Demonstrating rigor using thematic analysis: a hybrid approach of inductive and deductive coding 
and theme development. International Journal of Qualitative Methods, 5 (1), March, 2006.

Fundação Dom Cabral (2005a) Portfólio 2005 - Soluções educacionais inovadoras. Portfólio. Belo Horizonte: Fundação Dom Cabral, 2005.

Fundação Dom Cabral (2005b) CTE - Centro de Tecnologia Empresarial - Apresentação da parceria 2005. Relatório. Fundação Dom Cabral, 2005.

Hung, D., \& Nichani, M. (2001) Constructivism and e-learning: balancing between the individual and social levels of cognition. Educational Technology, 41(2): 40-44.

Kaiser, R. B., \& Kaplan, R. B. (2006) The deeper work of executive development: outgrowing sensitivities. Academy of Management Learning \& Education. Vol. 5, No. 4, 463-483.

Kogut, B. (1988) Joint ventures: theoretical and empirical perspectives. Strategic Management Journal, 9: 319-32, 1988.

Lane, C., \& Bachmann, R. (1998) Trust within and between organizations. Oxford University Press.

Larochelle, M., Bednarze, N., \& Garrison, J. W. (1998). Constructivism and Education. Cambridge University Press.

Mclntyre, J. R., \& Alon, I. (Eds.) (2005) Business and Management Education in Transitioning and Developing Countries: a Handbook. Armonk, NY: ME Sharpe.

Merriam, S. B., \& Caffarella R. S. (1991) Learning in Adulthood: a comprehensive guide. San Francisco: Jossey-Bass.

Pless, N. M., Maak, T., \& Stahl G. K. (2011) Developing Responsible Global Leaders Through International Service-Learning Programs: The Ulysses Experience. Academy of Management Learning \& Education. June 10:2 237-260.

Rock, I., \& Palmer S. (1990) The legacy of Gestalt Psychology. Scientific American. December, 48-61. 
Rousseau, D., \& Mccarthy, S. (2007) Educating managers from an evidence-based perspective. Academy of Management Learning \& Education. Vol. 16, No. 1, 84-101.

Skinner, B.F. (1935) The generic nature of the concepts of stimulus and response. Journal of General Psychology. 12, 40-65.

Thompson, J. D. (1967) Organization in Action. McGraw-Hill.

Van Maanen, J. (1978) People processing: strategies of organizational socialization. Organizational Dynamics, 64-82.

Waller, M.J., Lei, Z., \& Pratten, R. (2014). Focusing on teams in crisis management education: An integration and simulation-based approach. Academy of Management Learning \& Education. June, 13:2 208-221.

Artigo recebido em: 12/05/2014

Aprovado em: 26/06/2014 